\title{
Dependency Between the Total and Effective Imperviousness for Residential Quarters of the Lviv City
}

\author{
Volodymyr Zhuk ${ }^{1 *}$, Lesya Vovk', Ivan Matlai' ${ }^{1}$ Ihor Popadiuk'1 Ihor Mysak', \\ Vadym Fasuliak' \\ ${ }^{1}$ Institute of Civil Engineering and Building Systems, Lviv Polytechnic National University, Ukraine \\ * Corresponding author's e-mail: volodymyr.m.zhuk@lpnu.ua
}

\begin{abstract}
A detailed hydrologic analysis was performed using geographic information systems and field investigations for thirty residential quarters in the Franko district of the Lviv city, Ukraine. All investigated quarters are located at the territory of the Baltic Sea catchment of the Lviv city, and the surface runoff from this area flows to the Lviv wastewater treatment plant. The total area of the investigated sub-catchment is 348.5 ha, including $58.46 \%$ of impervious covers, $41.17 \%$ of green spaces and $0.37 \%$ of water bodies. The share of total impervious surfaces for each of the 30 analyzed quarters varies from 0.329 to 0.929 , and the effective imperviousness - from 0.222 to 0.917 . The correlation between the total and effective imperviousness was described by the power law dependency $p_{e f}=\left(p_{t o t}\right)$ n. Two approaches were used to describe the relationship between the total and the effective imperviousness: 1 ) using all 30 empirical results for each quarter; 2) using the average values of the imperviousness of the total subcatchment. The obtained values of the power law exponent for these two empirical approaches are $n_{1}=1.308$ and $n_{2}=1.275$, respectively or $7.2 \%$ and $9.6 \%$ less, respectively, comparing to the corresponding value $n=1.41$ in the Livingston's \& Veenhuis' approximation, obtained for 14 different highly urbanized quarters of Denver city. On the other hand, the power law exponents are $3.9 \%$ and $1.3 \%$ higher, respectively, comparing to the corresponding value $n=1.259$ in the approximation for the $900 \mathrm{~km}^{2}$ semi-urban watershed in Marion County, Georgia, USA.
\end{abstract}

Keywords: total imperviousness, effective imperviousness, stormwater modelling, surface runoff.

\section{INTRODUCTION}

The increase of impervious surface areas as a result of the urbanization process has a significant effect on the hydrologic cycle and on the ecological status of surface water bodies (European waters, 2018). The high content of organic contaminants in the surface runoff leads to the harmful changes in the qualitative composition of water in rivers, ponds and lakes, causing their eutrophication and rapid growth of cyanobacteria (Babko et al., 2019, Malovanyy et al., 2019, Malovanyy et al., 2016).

Urban imperviousness is one of the most principal indicators for stormwater modelling. A number of previous investigations proved that the effective or directly connected impervious area is more adequate parameter of catchment's stormwater infiltration potential, comparing to the total impervious area. The problem is that simple field investigation of effective imperviousness for large scale urbanized catchments is a highly expensive procedure. The simplest way to solve this problem is deriving of the general dependencies between the total and effective imperviousness. At the same time, there are some unsolved problems concerning the allowable ranges of such dependences in terms of the functional purpose of the territory and in the context of the different geographical location of the city, affecting both the climatic parameters as well as the local codes and regulations of stormwater drainage systems planning and installation.

The constantly growing part of impervious covers as a result of the urbanization process has a significant impact on the hydrological cycle 
of the drainage basin. In 2005, the total area of urbanized territories in the world was about 3\% of the total land area of the Earth (Laconte and Gossop, 2016). The proportion of impervious surfaces is one of the most important input parameters in the Stormwater modelling. A number of previous studies have shown that an effective or total imperviousness is a more adequate factor characterizing the stormwater runoff entering the sewer system, compared to the total imperviousness (Alley and Veenhuis, 1983; Lee and Heaney, 2003; Zhuk et al., 2018).

The following methods are used to investigate the territory according to the types of coverage: the cameral analysis of the surface distribution by the types of cover based on the satellite images of the terrain; full-scale survey with specification of the boundaries of cover of different types with establishing the peculiarities of connection of different sites to the centralized drainage network (Lee and Heaney, 2003; Zhuk et al., 2018); statistical sampling method (Zhuk, 2018), methods of spectral analysis of surfaces (Stathakis et al., 2012); the use of common functional dependencies (Alley and Veenhuis, 1983; Lee and Heaney, 2003). The impervious surface fraction images were extracted from remote sensing images by applying a feature extracted index following the V - I - S model (Sun et al., 2016). Each of these methods has its advantages and disadvantages. The methods that use the GIS resources have significant errors in recognizing cover types due to the effects of shading, overlay, or masking (Ebrahimian et al., 2016; Ebrahimian et al., 2018). The most accurate method of determining the type of covers is a full-scale survey, but this technique is expensive and time-consuming to implement.

In order to simplify the task, without losing the integrity of the problem, the relationships between the general and effective imperviousness are used. At the same time, some questions remain about the permissible ranges of applying such dependencies in terms of the functional purpose of the territory and in the context of the different geographical location of the city, which affects both the climatic parameters and local rules and codes for planning and arrangement of the stormwater drainage systems.

Alley and Veenhuis (1983) performed a detailed analysis of the impervious surfaces for the drainage basin by the type of connection to the stormwater drainage network, dividing the total impervious surfaces into those directly connected to the sewer network concept or the so-called effective impervious areas (EIA) and not connected to the sewer network impervious areas (NCIA). This approach allows for a more complete description of stormwater hydrology within an urbanized catchment. On the basis of the deep analysis and generalization of the results of the study of 14 highly urbanized districts of Denver (USA), a formula to determine the proportion of EIA depending on the share of total impervious areas (TIA) (Alley and Veenhuis, 1983) was obtained, characterized by a coefficient of determination $\mathrm{R}^{2}=0.98$ :

$$
p_{e f}=p_{t o t}^{1.41}
$$

where: $p_{\text {tot }}-$ total imperviousness,

$p_{e f}$-effective imperviousness.

Wenger et al. (2008) shows the empirical relationship between the EIA and TIA based on the surveys of 15 cities with the area of 25-70 ha in Georgia, USA:

$$
p_{e f}=1.046 p_{t o t}-0.0623
$$

A similar linear empirical relationship is obtained by Roy and Shuster (2009):

$$
p_{e f}=0.627 p_{t o t}-0.0186
$$

The processing of the in-situ data for a large semi-urbanized catchment in Marion County (USA), consisting of 100 identical sections with a total area of $900 \mathrm{~km}^{2}$ (Yang et al., 2011), yielded an approximate power dependence

$$
p_{\text {ef }}=p_{\text {tot }}^{1.259}
$$

with a comparatively low value of the coefficient of determination $\mathrm{R}^{2}=0.873$, which is caused by the large variation of natural data, especially for the sub-catchments with low and medium levels of urbanization, i.e. in the range $p_{t o t} \leq 0.4$.

The direct application of dependencies (1) to (4) to calculate EIA is problematic due to the significant differences in the urban planning standards and practices in different countries of the world. In this regard, a detailed study and analysis requires the dependencies between the total and effective imperviousness for Ukrainian cities and towns. Obtaining the dependencies similar to (1) - (4) will significantly reduce the time spent on field research to determine the types of covers 
of urban catchments and increase the level of reliability of the relevant hydrological and hydraulic models of the stormwater runoff.

The purpose of the paper was to determine experimentally the relationship between the total and effective imperviousness for the stormwater modelling from the territory of 30 residential quarters of the Franko district of the Lviv city.

In order to achieve this goal, the following tasks were solved:

- a full-scale survey of the territory was performed, the boundaries of sites with different types of surface covers were specified;

- peculiarities of connection of different sites to the centralized drainage network were established;

- relationships between the total and effective imperviousness for the 30 residential quarters of the Lviv city were obtained.

\section{MATERIALS AND METHODS}

The object of the study are the residential quarters of Franko district - one of the central districts of the Lviv city (Fig. 1). Within the Franko district, a total area of 370.2 ha has been defined, which was divided into 32 quarters for the convenience of the survey. All the investigated quarters are located at the territory of the Baltic Sea catchment of Lviv city, and the surface runoff from this area flows into the combined sewerage system of Lviv and further - directly to the Lviv wastewater treatment plant (WWTP). The boundaries of the quarters are located at the axis of the streets, the total areas of individual quarters range from 5.2 ha to 23.8 ha. Among the surveyed quarters, there are various types of residential development: modern multi-storey buildings (2000-2019) with a high percentage of improved waterproof covers that are directly connected to the sewerage network (for example, the F-31 quarter within Kn.Olga Str., L. Kobylitsa Str. and Kholodnoyarska Str. - with the predominance of modern multi-storey buildings and the proper number of stormwater inlets installed); quarters with 2-3 storey buildings from the period of 1960-1980 with significant green spaces, buildings with outer gutters that divert rainwater to adjacent green spaces, and roads with very rare stormwater inlets (e.g., quarter F-32 within the Kn.Olga Str., Arkasa Str., Kovaleva Str.). Most of the investigated territories are residential quarters, typical for a highly urbanized city, with medium

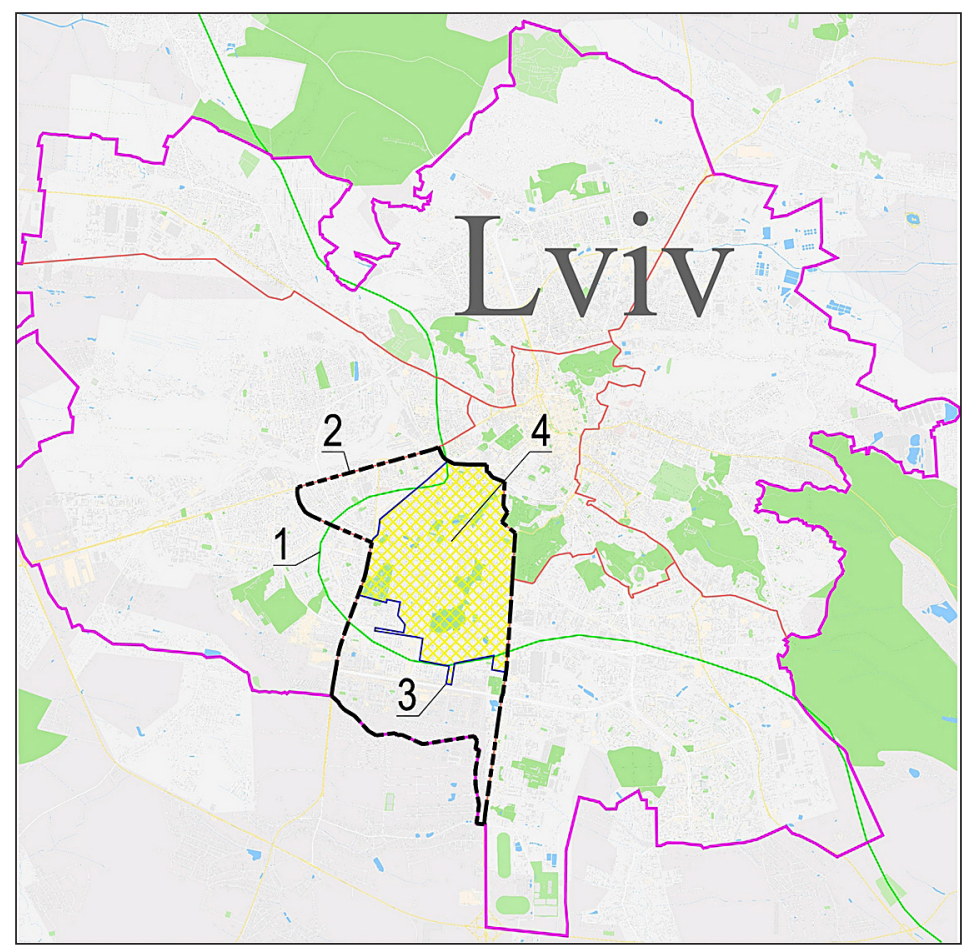

Fig. 1. The layout of the object of research:

1 - main European watershed (geographical watershed),

2 - borders of the Franko district of the Lviv city, 3 - technical watershed of the

Franko district, 4 - part of the Franko district, belonging to the Baltic Sea catchment 
or multi-storey buildings, asphalt road pavements and a high degree of landscaping.

The on-site study include the performing of the full-scale survey, specifying the borders of covers of different types and establishing the peculiarities of connection of the respective areas to the combined sewerage network of Lviv.

After a detailed analysis of the quarters, their classification by functional purpose was established: 30 residential quarters located on an area of $348.52 \mathrm{ha}$, or $94.1 \%$ of the total area; one quarter with educational, academic and administrative buildings (9.95 ha, 2.7\%); one quarter of sports and recreational territory (11.72 ha, 3.2\%). In this paper, the relationship between the total and effective imperviousness only from the residential areas of the Lviv was investigated, so the quarter F-22 (the territory of educational and economic buildings of the Ukrainian National Forestry University and the quarter F-14 (sports and recreation complex "Medic"), were not taken into account when obtaining the following results.

The total area of each quarter was represented as a sum of: 1) impervious areas directly connected to the drainage network (DCIA); 2) non-connected impervious areas (NCIA); 3 ) soil covers and green spaces. The field survey data were presented on an electronic map in scale of 1: 2000, the areas of individual sections of the territory were determined analytically to the nearest $1 \mathrm{~m}^{2}$.

\section{RESULTS AND DISCUSSION}

As a result of full-scale survey of the territory, the boundaries and types of covers of the quarters were defined. This time-consuming work eliminates errors caused by shading or distortion in satellite images when surveyed using the GIS-based maps (Gironas et al., 2010; Sanzana et al., 2017; Zhuk et al., 2018). During the study, the peculiarities of connection of different sites to the centralized drainage network for each quarter were determined. This enabled to analyze the ways of surface runoff to the city drainage network of Lviv.

The quantitative results of the cover type analysis were summarized in separate tables for each of the 30 residential quarters. In Table 1, for example, the results for the quarter F-2 are presented (in the boundaries of Polytechnic Str., General Chuprynka Str., Kyivska Str. and St. Bandera $\mathrm{Str})$. In the Table 1 areas of cover types are represented both in dimensional and non-dimensional units relative to the total area of the quarter. The graphical representation of the results of the field study of the quarter F-2 is shown in Figure 2.

In Table 2, the areas and proportions of total impervious surfaces $p_{\text {tot }}$ and effective imperviousness $p_{e f}$ for each of the 30 surveyed residential quarters in the Franko district of the Lviv city were summarized.

The total area of the surveyed residential quarters is 348.5 hectares, including $58.46 \%$ of total impervious covers, $41.17 \%$ of soil covers and green spaces, and $0.37 \%$ of water bodies. The proportion of total impervious areas for individual quarters varies from 0.329 to 0.929 , and the corresponding proportion of the effective impervious areas ranges from 0.222 to 0.917 . This is due to the significant difference in the types of development of individual quarters, which is

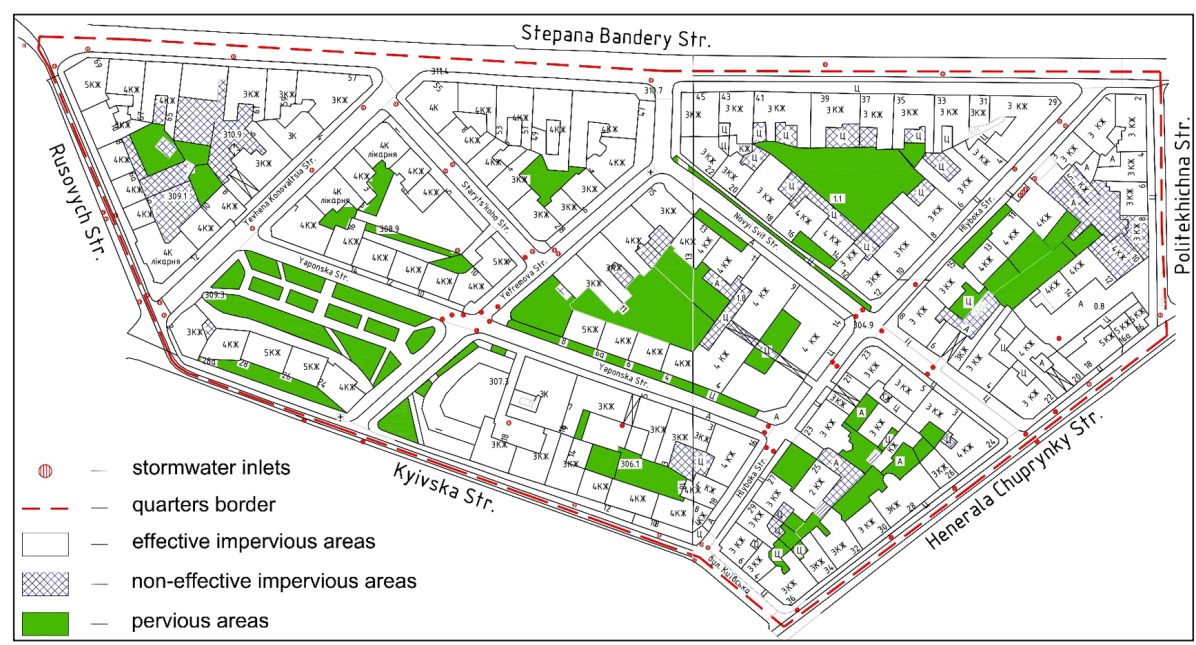

Fig. 2. The results of a full-scale study of the types of coverage of the residential quarter F-2 (in the boundaries of Politekhnichna Str., Heneral Chuprynka Str., Kyivska Str. and St. Bandera Str.) 
Table 1. Area information for a residential quarter F-2 (Politekhnichna Str., Heneral Chuprynka Str., Kyivska Str. and St. Bandera Str.)

\begin{tabular}{|c|c|c|c|c|}
\hline \multirow{2}{*}{ No. } & \multirow{2}{*}{ Type of the cover } & \multicolumn{2}{|c|}{ Area } & \multirow{2}{*}{ Dimensionless area $[\%]$} \\
\hline & & {$\left[\mathrm{m}^{2}\right]$} & [ha] & \\
\hline 1 & Directly connected impervious areas & 76737 & 7.674 & 80.92 \\
\hline 2 & Non-connected impervious areas & 5288 & 0.529 & 5.58 \\
\hline 3 & Soil covers and green spaces & 12802 & 1.280 & 13.50 \\
\hline 4 & Total impervious areas & 82025 & 8.203 & 86.50 \\
\hline 5 & Total area & 94827 & 9.483 & 100.00 \\
\hline
\end{tabular}

characteristic of the large cities that have been formed for decades and even centuries.

Two approaches were used to describe the relationship between the total and effective imperviousness: 1) approximation for all 30 empirical results for each quarter; 2) approximation of the average values of the total and effective imperviousness of the total sub-catchment.

The empirical dependencies between the total and effective imperviousness for 30 investigated residential quarters in Lviv were obtained with the normalized power functions methodology

$$
p_{e f}=p_{t o t}^{n}
$$

The sense of the normalization is the automatic realization of the obvious upper boundary condition: effective imperviousness $p_{e f}=1$ when the total imperviousness is $p_{\text {tot }}=1$.

The results of determining the exponent $n$ with first approach are shown in Fig. 3. The result is the value of the exponent $n=1.308$, which is $7.2 \%$ less than in the formula (1) and $3.9 \%$ more comparing the dependence (4).

Thus, for all 30 surveyed residential quarters of Lviv next power law correlation is obtained:

$$
p_{e f}=p_{t o t}^{1.308}
$$

By the second approach, the value of $n$ is determined analytically using the average values of the effective and total imperviousness of all 30 residential quarters together:

$$
n=\ln \left(p_{\text {ef.mid }}\right) / \ln \left(p_{\text {tot.mid }}\right)
$$

where: $p_{\text {tot.mid }}-$ the average proportion of total impervious areas for the entire investigated sub-catchment with total area 348.5 ha, $p_{\text {tot.mid }}=0.5846$,

$p_{\text {ef.mid }}$ - the average proportion of effective impervious areas for the entire sub-catchment,

$p_{\text {ef.mid }}=0.5045$.

Thus, the power law exponent $n$ in the dependence (5) when using the second, averaged approach, is obtained equal to $n=1.275$, which is $9.6 \%$ less than in the formula (1) and $1.3 \%$ more comparing the dependence (4).

The obtained results can be applied in the modeling of the stormwater drainage systems in Ukraine, taking into account local regulatory requirements and city planning specifics. The topic of the impact of urban functional purpose on the relationship between the total and effective

Table 2. Total imperviousness $p_{\text {tot }}$ and effective imperviousness $p_{e f}$ for the 30 surveyed residential quarters in the Franko district of the Lviv city

\begin{tabular}{|c|c|c|c|c|c|c|c|c|c|c|}
\hline Item & F-1 & F-2 & F-3 & F-4 & F-5 & F-6 & F-7 & F-8 & F-9 & F-10 \\
\hline$p_{\text {tot }}$ & 0.929 & 0.865 & 0.725 & 0.456 & 0.813 & 0.719 & 0.753 & 0.750 & 0.601 & 0.478 \\
\hline$p_{\text {ef }}$ & 0.917 & 0.809 & 0.677 & 0.334 & 0.792 & 0.684 & 0.712 & 0.709 & 0.487 & 0.390 \\
\hline$F_{\text {tot }}[\mathrm{ha}]$ & 8.21 & 9.48 & 6.78 & 10.24 & 14.64 & 15.00 & 11.10 & 9.66 & 15.50 & 19.24 \\
\hline
\end{tabular}

\begin{tabular}{|c|c|c|c|c|c|c|c|c|c|c|}
\hline Item & F-11 & F-12 & F-13 & F-15 & F-16 & F-17 & F-18 & F-19 & F-20 & F-21 \\
\hline$p_{\text {tot }}$ & 0.597 & 0.736 & 0.564 & 0.444 & 0.703 & 0.755 & 0.535 & 0.463 & 0.507 & 0.559 \\
\hline$p_{\text {ef }}$ & 0.560 & 0.706 & 0.482 & 0.309 & 0.592 & 0.678 & 0.486 & 0.343 & 0.431 & 0.349 \\
\hline$F_{\text {tot }}$ hal & 7.51 & 8.82 & 8.85 & 7.88 & 11.39 & 23.80 & 13.92 & 5.20 & 6.96 & 8.20 \\
\hline
\end{tabular}

\begin{tabular}{|c|c|c|c|c|c|c|c|c|c|c|}
\hline Item & F-23 & F-24 & F-25 & F-26 & F-27 & F-28 & F-29 & F-30 & F-31 & F-32 \\
\hline$p_{\text {tot }}$ & 0.455 & 0.453 & 0.424 & 0.386 & 0.747 & 0.344 & 0.337 & 0.329 & 0.685 & 0.444 \\
\hline$p_{\text {ef }}$ & 0.364 & 0.399 & 0.358 & 0.263 & 0.699 & 0.312 & 0.248 & 0.274 & 0.586 & 0.222 \\
\hline$F_{\text {tot }}[\mathrm{ha}]$ & 11.45 & 8.79 & 7.99 & 9.60 & 10.54 & 14.72 & 14.70 & 15.20 & 17.50 & 15.67 \\
\hline
\end{tabular}




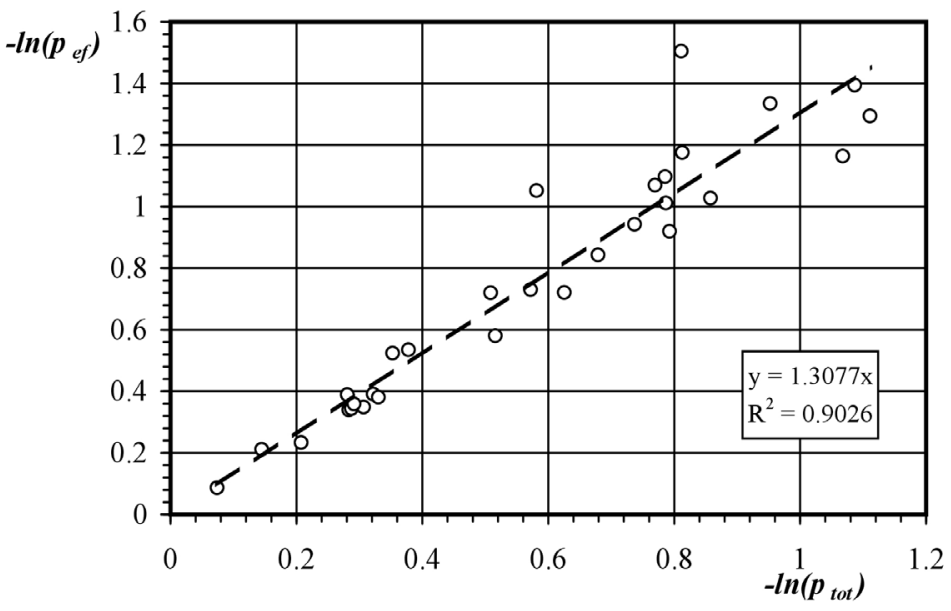

Fig. 3. Logarithmic dependence between the effective and total imperviousness for 30 residential quarters in the Franko district of the Lviv city

imperviousness of the urbanized catchments still remains open.

\section{CONCLUSIONS}

Increase of the impervious surface areas as result of the urbanization process has a significant effect on the hydrologic cycle and on the ecological status of surface water bodies. Urban imperviousness is one of the most principal indicators for the stormwater modeling.

A detailed hydrologic analysis was performed using geographic information systems and field investigations for thirty residential quarters in the Franko district of the Lviv city, Ukraine. All the investigated quarters are located at the territory of the Baltic Sea catchment of the Lviv city, and the surface runoff from this area flows into the combined sewerage system of Lviv and further to the Lviv wastewater treatment plant. The total area of the investigated sub-catchment is $348.5 \mathrm{ha}$, including $58.46 \%$ of impervious covers, $41.17 \%$ of soil covers and green spaces and $0.37 \%$ of water bodies. The share of total impervious surfaces for each of 30 analyzed quarters varies from 0.329 to 0.929 , and the effective imperviousness - from 0.222 to 0.917 .

The correlations between the total and effective imperviousness were described by the power law dependency $p_{e f}=\left(p_{t o}\right)^{n}$ similar to (Alley and Veenhuis, 1983, Yang et al., 2011). Two

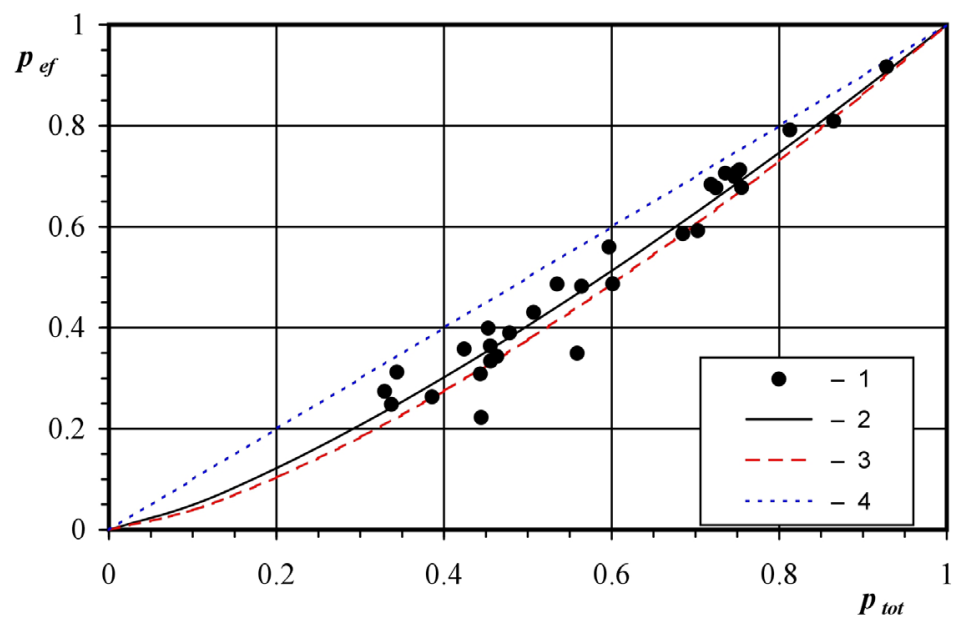

Fig. 4. Dependencies of effective and total imperviousness:

1 - full-scale results for 30 residential quarters in the Franko district of the Lviv city, 2 - obtained approximation (6), 3 - approximation (1) for the Denver city (Alley and Veenhuis, 1983), $4-$ asymptote $p_{e f}=p_{t o t}$ 
approaches were used to describe the relationship between the total and effective imperviousness:

1. using all 30 empirical results for each quarter (obtained value of the power law exponent for this approach $n_{1}=1.308$ );

2. using the average value of the imperviousness of the total sub-catchment (value of the power law exponent for this approach $n_{2}=1.275$ ).

The obtained empirical results are $7.2 \%$ and $9.6 \%$ lesser respectively, comparing the corresponding value $n=1.41$ in the Livingston's and Veenhuis' approximation, obtained for 14 different highly urbanized quarters of Denver city. On the other hand, the obtained power law exponents are $3.9 \%$ and $1.3 \%$ higher, respectively, comparing the corresponding value $n=1.259$ in the approximation for the $900 \mathrm{~km}^{2}$ semi-urban watershed in Marion County, Georgia, USA.

The obtained correlation between the total and effective imperviousness for residential quarters in the Lviv city can be used widely as the principle parameter of sub-catchment cover in the stormwater drainage systems modeling.

\section{REFERENCES}

1. Alley, W.M., Veenhuis, J.E.: 1983. Effective impervious area in urban runoff modeling. Journal of Hydraulic Engineering, 109 (2), 313-319.

2. Babko, R., Szulżyk-Cieplak, J., Danko Y., Duda, S., Kirichenko-Babko M., Łagód G. Effect of stormwater system on the receiver. Journal of Ecological Engineering, 20(6), 52-59, 2019. https://doi. org/10.12911/22998993/109433

3. Ebrahimian, A., Gulliver, J.S., Wilson, B.N.: 2018. Estimating effective impervious area in urban watersheds using land cover, soil character and asymptotic curve number. Hydrological Sciences Journal, 63(4), 513-526.

4. Ebrahimian, A., Wilson, B.N., Gulliver, J.S.: 2016. Improved methods to estimate the effective impervious area in urban catchments using rainfall-runoff data. Journal of Hydrology, 536, 109-118.

5. European waters. Assessment of status and pressures 2018. EEA Report No7/2018. European Environment Agency, 85.

6. Gironas, J., Niemann, J.D., Roesner, L.A., Rodriguez, F., Andrieu, H.: 2010. Evaluation of methods for representing urban terrain in storm-water modeling. Journal of Hydrological Engineering, 15 (1), 1-14.

7. Laconte, P., Gossop, C.: 2016. Sustainable cities.
Assessing the performance and practice of urban environments. I.B.Tauris, $242 \mathrm{p}$.

8. Lee, J.G., Heaney, J.P.: 2003. Estimation of Urban Imperviousness and its impacts on storm water systems. Journal of Water Resources Planning and Management, 129(5), 419-426.

9. Malovanyy, M., Moroz, O., Hnatush, S., Maslovska, O., Zhuk, V., Petrushka, I., Nykyforov, V., Sereda, A.: 2019. Perspective technologies of the treatment of the wastewaters with high content of organic pollutants and ammoniacal nitrogen. Journal of Ecological Engineering, 20 (2), 8-15. https:// doi.org/10.12911/22998993/94917

10. Malovanyy, M., Nikiforov, V., Kharlamova, O., Synelnikov, O.: 2016. Production of renewable energy resources via complex treatment of cyanobacteria biomass. Chemistry \& Chemical Technology, 10 (2), 251-254. https://doi.org/10.23939/ chcht10.02.251

11. Roy, A.H., Shuster, W.D.: 2009. Assessing Impervious Surface Connectivity and Applications for Watershed Management. Journal of the American Water Resources Association, 45(1), 198-209.

12. Sanzana, P., Gironas, J., Braud, I. et al.: 2017. A GISbased urban and Peri-urban landscape representation toolbox for hydrological distributed modelling. Environmental Modelling and Software, 91, 168-185.

13. Stathakis, D., Perakis, K., Savin, I.: 2012. Efficient segmentation of urban areas by the VIBI. International Journal of Remote Sensing, 33 (20), 6361-6377.

14. Sun, G., Chen, X., Jia, X., Yao, Y., Wang, Z.: 2016. Combinational Build-Up Index (CBI) for Effective Impervious Surface Mapping in Urban Areas. IEEE Journal of Selected Topics in Applied Earth Observations and Remote Sensing, 9(5), 2081-2092.

15. Wenger, S.J., Peterson, J.T. et al.: 2008. Stream fish occurrence in response to impervious cover, historic land use, and hydrogeomorphic factors. Canadian Journal of Fisheries and Aquatic Sciences, 65(7), 1250-1264.

16. Yang, G., Bowlinga, L.C., Cherkauer, K.A., Pijanowski, B.C.: 2011. The impact of urban development on hydrologic regime from catchment to basin scales. Landscape and Urban Planning, 103, 237- 247.

17. Zhuk, V.: 2018. Statistical method for determining the distribution of surfaces by type of coverage on large urbanized drainage basins. Instal, 3(393), 45-48.

18. Zhuk, V.M., Vovk, L.I., Matlai, I.I., Popadiuk, I.Yu.: 2018. Correlation between the total and effective imperviousness in stormwater modelling. Scientific Bulletin of UNFU, 28(10), 92-95 (in Ukrainian). 